\title{
Kinetics of Radical Polymerization of Vinyl Acetate Initiated by 1-Azobisphenylethane
}

\author{
Katsukiyo ITO \\ Government Industrial Research Institute, Nagoya, \\ Kita-ku, Nagoya 462, Japan
}

(Received September 26, 1983)

\begin{abstract}
Vinyl acetate was polymerized using high concentrations of 1-azobisphenylethane (APE) as the initiator. Its polymerization rate was 30 times slower than that initiated by $2,2^{\prime}-$ azobisisobutyronitrile, although the production rates of primary radicals were the same for both initiators. Such a slow rate can be explained kinetically on the assumption that the rate constant $\left(k_{\mathrm{i}}\right)$ for the addition of phenylethyl radicals to the monomer is much smaller than the propagation rate constant $\left(k_{\mathrm{p}}\right)$, where $k_{\mathrm{ti}} / k_{\mathrm{i}} k_{\mathrm{p}}=6.07 \times 10^{-11} \exp (12500 / T) \mathrm{dm}^{3} \mathrm{~mol}^{-1} \mathrm{~s}^{-1}\left(k_{\mathrm{ti}}\right.$, primary radical termination rate constant and $T$, absolute temperature). The molecular weights of the polymers were controlled by the transfer of propagating radicals to APE where the transfer constant was estimated to be $\mathrm{C}_{\mathrm{tr}}=31 \exp (-1860 / T)$.

KEY WORDS Vinyl Acetate / 1-Azobisphenylethane / Polymerization Rate / Molecular Weight / Kinetics / Primary Radical / Addition to Monomer / Termination / Transfer to Initiator /
\end{abstract}

1-Azobisphenylethane (APE) is an initiator for radical polymerizations ${ }^{1}$ and thermally decomposes to yield 1-phenylethyl radicals (PER). The rate of cross termination in copolymerization between methacrylonitrile and styrene was compared with that of the bimolecular reaction between dimethylcyanomethylradicals and PER because of its similarity in structure $\left(\mathrm{CH}_{3} \mathrm{CHC}_{6} \mathrm{H}_{5}\right)$ to the end radical of polystyrene. ${ }^{2}$ Further, the chain length dependence of the termination rate for the polymerization of styrene initiated by PER was analyzed on the assumption that PER is a radical with $n=1 .^{3,4}$

In this article, the polymerization of vinyl acetate (VAc) in the presence of high concentration APE is reported. The rate was 30 times slower than that initiated by $2,2^{\prime}$-azobisisobutyronitrile (AIBN), although both the production rates of primary radicals were the same. Further, it was proportional to $[\mathrm{M}]^{1,5 \sim 2}$, but independent of [APE]. These phenomena can be explained by assuming that the rate of addition to VAc is very slow compared with that of propagation. The molecular weight was approximately proportional to $[\mathrm{M}] /[\mathrm{APE}]$ and independent of the polymerization rate. This indicates the molecular weight to be controlled by the transfer to APE. The radical produced by this transfer may be stable, and therefore will hardly adds to VAc.

\section{THEORY}

Polymerization scheme is as follows:

Initiation:

$$
\begin{array}{ll}
C \rightarrow 2 R & 2 f k_{\mathrm{d}}[\mathrm{C}] \\
R+M \rightarrow N_{1} & k_{\mathrm{i}}[\mathrm{R}][\mathrm{M}]
\end{array}
$$

Propagation:

$$
N_{n}+M \rightarrow N_{n+1} \quad k_{\mathrm{p}}[\mathrm{N}][\mathrm{M}]
$$

Termination: 


$$
\begin{array}{ll}
N+N \rightarrow \text { polymers } & \bar{k}_{\mathrm{t}}[\mathrm{N}]^{2} \\
N+R \rightarrow \text { polymer } & k_{\mathrm{ti}}[\mathrm{N}][\mathrm{R}] \\
T_{\mathrm{C}}+N \rightarrow \text { polymer } & k_{\mathrm{trt}}[\mathrm{N}]\left[\mathrm{T}_{\mathrm{C}}\right]
\end{array}
$$

Transfer:

$$
\begin{array}{ll}
N+C \rightarrow T_{\mathrm{C}}+\text { polymer } & k_{\mathrm{trC}}[\mathrm{N}][\mathrm{C}] \\
N+M \rightarrow T_{\mathrm{M}}+\text { polymer } & k_{\mathrm{trM}}[\mathrm{N}][\mathrm{M}] \\
N+S \rightarrow T_{\mathrm{S}}+\text { polymer } & k_{\mathrm{trS}}[\mathrm{N}][\mathrm{S}]
\end{array}
$$

where $T_{\mathrm{M}}$ and $T_{\mathrm{S}}$ immediately add to monomers, but not $T_{\mathrm{C}}$.

The polymerization rate can then be expressed as

$$
\begin{aligned}
R_{\mathrm{p}} & =k_{\mathrm{p}}[\mathrm{M}][\mathrm{N}]+k_{\mathrm{i}}[\mathrm{R}][\mathrm{M}] \\
& \simeq k_{\mathrm{p}}[\mathrm{M}][\mathrm{N}]
\end{aligned}
$$

The material balance gives

$$
\begin{aligned}
\frac{\mathrm{d}[\mathrm{R}]}{\mathrm{d} t}= & 2 f k_{\mathrm{d}}[\mathrm{C}]-k_{\mathrm{i}}[\mathrm{R}][\mathrm{M}]-k_{\mathrm{ti}}[\mathrm{R}][\mathrm{N}]=0 \\
\frac{\mathrm{d}[\mathrm{N}]}{\mathrm{d} t}= & k_{\mathrm{i}}[\mathrm{R}][\mathrm{M}]-k_{\mathrm{t}}[\mathrm{N}]^{2} \\
& -k_{\mathrm{ti}}[\mathrm{N}][\mathrm{R}]-k_{\mathrm{trC}}[\mathrm{N}][\mathrm{C}] \\
& -k_{\mathrm{trt}}\left[\mathrm{T}_{\mathrm{C}}\right][\mathrm{N}]=0 \\
\frac{\mathrm{d}\left[\mathrm{T}_{\mathrm{C}}\right]}{\mathrm{d} t}= & k_{\mathrm{trC}}[\mathrm{N}][\mathrm{C}]-k_{\mathrm{trt}}[\mathrm{N}]\left[\mathrm{T}_{\mathrm{C}}\right]=0
\end{aligned}
$$

It is assumed that

$$
k_{\mathrm{ti}}[\mathrm{N}][\mathrm{R}] \gg \bar{k}_{\mathrm{t}}[\mathrm{N}]^{2}
$$

This assumption was very useful for treating the polymerization rates of VAc initiated by AIBN, ${ }^{5}$ and those of styrene and methylmethacrylate initiated by azobisdiphenylmethane ${ }^{3}$ when [C] was high and [M] was low. Now, the concentration of polymer radical is shown as

$$
\begin{aligned}
{[\mathrm{N}] } & =\left(\frac{k_{\mathrm{i}}[\mathrm{M}]}{2 k_{\mathrm{ti}}}+\frac{f k_{\mathrm{d}}}{2 k_{\mathrm{trC}}}\right) \\
& \times\left\{\left[1+\frac{2 f k_{\mathrm{d}}[\mathrm{M}]}{k_{\mathrm{ti}} k_{\mathrm{trC}}\left(\frac{k_{\mathrm{i}}[\mathrm{M}]}{k_{\mathrm{ti}}}+\frac{f k_{\mathrm{d}}}{k_{\mathrm{trC}}}\right)^{2}}\right]^{1 / 2}-1\right\}
\end{aligned}
$$

$$
\simeq \frac{k_{\mathrm{i}}[\mathrm{M}] / k_{\mathrm{ti}}}{1+\left(C_{\mathrm{trC}} / f k_{\mathrm{d}}\right)\left(k_{\mathrm{i}} k_{\mathrm{p}} / k_{\mathrm{ti}}\right)[\mathrm{M}]}
$$

The latter was derived from the former, using a familiar approximation as $(1+2 x)^{1 / 2} \simeq 1+$ $x-\cdots$. Accordingly, the relationship between [M] and $R_{\mathrm{p}}$ is

$$
\frac{[\mathrm{M}]^{2}}{R_{\mathrm{p}}} \simeq \frac{k_{\mathrm{ti}}}{k_{\mathrm{i}} k_{\mathrm{p}}}+\frac{C_{\mathrm{trC}}}{f k_{\mathrm{d}}}[\mathrm{M}]
$$

For a very small value of $[\mathrm{M}]$, eq 18 becomes one already derived. ${ }^{5}$ The relationship between various reactants and chain length is given by

$$
\begin{aligned}
\frac{k_{\mathrm{p}}[\mathrm{M}][\mathrm{N}]}{\bar{n}}= & k_{\mathrm{ti}}[\mathrm{N}][\mathrm{R}]+k_{\mathrm{trt}}[\mathrm{N}]\left[\mathrm{T}_{\mathrm{C}}\right] \\
& +k_{\mathrm{trC}}[\mathrm{N}][\mathrm{C}]+k_{\mathrm{trC}}[\mathrm{N}][\mathrm{M}] \\
& +k_{\mathrm{trS}}[\mathrm{N}][\mathrm{S}]
\end{aligned}
$$

Using eq 12,13 , and 14 , eq 19 is rewritten as

$$
\begin{aligned}
\frac{1}{\bar{n}}-C_{\mathrm{trM}}-C_{\mathrm{trS}} \frac{[\mathrm{S}]}{[\mathrm{M}]}=2 C_{\mathrm{trC}} \frac{[\mathrm{C}]}{[\mathrm{M}]} \\
+\frac{\left(2 f k_{\mathrm{d}}[\mathrm{C}]\right) k_{\mathrm{ti}} / k_{\mathrm{i}} k_{\mathrm{p}}[\mathrm{M}]^{2}}{1+k_{\mathrm{ti}} R_{\mathrm{p}} / k_{\mathrm{i}} k_{\mathrm{p}}[\mathrm{M}]^{2}}
\end{aligned}
$$

\section{EXPERIMENTAL}

Commercial VAc and AIBN were purified by methods described in earlier papers. ${ }^{6,7} \mathrm{APE}$ was prepared as described before. ${ }^{1}$ Mixtures of VAc, an initiator, and ethyl acetate as the polymerization solvent were placed in an ampoule and degassed at about $10^{-3} \mathrm{mmHg}$ by the freeze-thaw technique. The molecular weight of polymers produced was rather small, as shown in Table I, and the weight loss on the purification of the polymers was thus not negligible. Further, the separation of APE from the polymers could not be carried out satisfactorily. Accordingly, the conversions were estimated by gel permeation chromatography (GPC). Ultimate conversions were less than $5 \%$. To calculate the $M_{n}$ and $M_{w}$ of poly(VAc), the GPC calibration curve for polystyrene was modified 
Polymerization of VAc Initiated by Azobisphenylethane

Table I. Polymerization of VAc initiated by APE

\begin{tabular}{|c|c|c|c|c|c|c|c|}
\hline$\frac{\text { Temp }}{{ }^{\circ} \mathrm{C}}$ & $\frac{[\mathrm{C}]}{\mathrm{moldm}^{-3}}$ & $\frac{[\mathrm{M}]}{\mathrm{moldm}^{-3}}$ & $\frac{10^{6} R_{\mathrm{p}}}{\mathrm{moldm^{-3 } \mathrm { s } ^ { - 1 }}}$ & $M_{n}$ & $M_{w}$ & $M_{w} / M_{n}$ & $2 C_{\mathrm{trC}}$ \\
\hline 53 & $\begin{array}{l}0.20 \\
0.20 \\
0.20\end{array}$ & $\begin{array}{l}5.18 \\
1.727 \\
0.576\end{array}$ & $\begin{array}{l}5.76 \\
0.851 \\
0.115\end{array}$ & 11830 & 23100 & 1.95 & 0.18 \\
\hline 60 & $\begin{array}{l}0.04 \\
0.10 \\
0.20 \\
0.20 \\
0.20 \\
0.20 \\
0.20 \\
0.20\end{array}$ & $\begin{array}{c}10.15 \\
10.05 \\
9.72 \\
4.08 \\
2.72 \\
1.82 \\
1.21 \\
0.807\end{array}$ & $\begin{array}{l}25.4 \\
30.8 \\
31.9 \\
9.19 \\
4.13 \\
2.23 \\
1.10 \\
0.506\end{array}$ & $\begin{array}{r}64350 \\
\\
22800 \\
8890 \\
5600 \\
4080 \\
2590\end{array}$ & $\begin{array}{r}129800 \\
43910 \\
18830 \\
12100 \\
8270 \\
5230\end{array}$ & $\begin{array}{l}1.99 \\
\\
1.92 \\
2.12 \\
2.18 \\
2.03 \\
2.02\end{array}$ & $\begin{array}{l}0.18 \\
0.19 \\
0.20 \\
0.18 \\
0.19\end{array}$ \\
\hline 70 & $\begin{array}{l}0.10 \\
0.10 \\
0.10 \\
0.10 \\
0.10\end{array}$ & $\begin{array}{l}9.78 \\
4.89 \\
2.45 \\
1.22 \\
0.612\end{array}$ & $\begin{array}{l}99.2 \\
35.3 \\
11.7 \\
4.16 \\
0.966\end{array}$ & $\begin{array}{r}30800 \\
14970 \\
7410 \\
3980\end{array}$ & $\begin{array}{r}60100 \\
30400 \\
15340 \\
8280\end{array}$ & $\begin{array}{l}1.95 \\
2.03 \\
2.07 \\
2.08\end{array}$ & $\begin{array}{l}0.25 \\
0.25 \\
0.26 \\
0.23\end{array}$ \\
\hline 80 & $\begin{array}{l}0.10 \\
0.10 \\
0.10 \\
0.10 \\
0.10\end{array}$ & $\begin{array}{l}9.64 \\
4.82 \\
2.41 \\
1.21 \\
0.612\end{array}$ & $\begin{array}{l}333 \\
113 \\
35.2 \\
10.0 \\
2.50\end{array}$ & $\begin{array}{r}27600 \\
15700 \\
7080 \\
3590\end{array}$ & $\begin{array}{r}56700 \\
29900 \\
14540 \\
6720\end{array}$ & $\begin{array}{l}2.05 \\
1.90 \\
2.05 \\
1.87\end{array}$ & $\begin{array}{l}0.28 \\
0.23 \\
0.23 \\
0.25\end{array}$ \\
\hline 90 & $\begin{array}{l}0.10 \\
0.10 \\
0.10 \\
0.10 \\
0.10\end{array}$ & $\begin{array}{l}9.49 \\
4.74 \\
2.37 \\
1.19 \\
0.593\end{array}$ & $\begin{array}{c}1098 \\
324 \\
96.2 \\
29.1 \\
4.40\end{array}$ & $\begin{array}{r}23500 \\
11460 \\
6320 \\
2670\end{array}$ & $\begin{array}{r}47800 \\
24600 \\
12040 \\
5680\end{array}$ & $\begin{array}{l}2.03 \\
2.15 \\
1.91 \\
2.12\end{array}$ & $\begin{array}{l}0.32 \\
0.32 \\
0.29 \\
0.34\end{array}$ \\
\hline
\end{tabular}

using $[\eta]=1.98 \times 10^{-4} M_{v}^{0.695}$ at $n \geq 60$ and $[\eta]=1.05 \times 10^{-3} M_{v}^{0.50}$ at $n<60$ in tetrahydrofuran at $38^{\circ} \mathrm{C}$. These equations were obtained using

$$
\begin{gathered}
{[\eta]=K M_{v}{ }^{\mathrm{a}}} \\
\frac{[\eta] M_{w}}{K_{\mathrm{s}}}=\left\{\sum_{j=1}^{\infty} w_{j} M_{j \mathrm{~s}}{ }^{\left[a\left(1+a_{\mathrm{s}}\right) /(1+a)\right]}\right\} \\
\left\{\sum_{j=1}^{\infty} w_{j} M_{j \mathrm{~s}}^{\left[\left(1+a_{\mathrm{s}}\right) /(1+a)\right]}\right\}
\end{gathered}
$$

Equation 22 was derived by replacing $M_{n}$ in Mahabadi and O'Driscoll's equation ${ }^{8}$ with $M_{w}$, and $M_{w}$ was determined by the light scattering method.

\section{RESULTS AND DISCUSSION}

The kinetic data obtained are shown in Table I. The polymerization rate was $3.19 \times$ $10^{-5} \mathrm{moldm}^{-3} \mathrm{~s}^{-1}$ for the bulk polymerization initiated by $\mathrm{APE}$ at $60^{\circ} \mathrm{C}$ and $[\mathrm{C}]=$ $0.200 \mathrm{~mol} \mathrm{dm}^{-3}$. With AIBN as the initiator, the rate was $106 \times 10^{-5} \mathrm{~mol} \mathrm{dm}^{-3} \mathrm{~s}^{-1}$ at $[\mathrm{C}]=$ $0.00647 \mathrm{moldm}^{-3}$. Even though $2 f k_{\mathrm{d}}[\mathrm{C}]=$ $3.26 \times 10^{-8} \mathrm{moldm}^{-3} \mathrm{~s}^{-1}$ in both the above cases, the polymerization rate initiated by APE was 30 times slower than that initiated by AIBN, where $f k_{\mathrm{d}}=1.63 \times 10^{-7} \mathrm{~s}^{-1}$ for APE and $5.04 \times 10^{-6}$ for AIBN. ${ }^{2}$ For $[\mathrm{APE}] \geq 0.1$ mol dm ${ }^{-3}$, the polymerization rate was proportional to $[\mathrm{M}]^{1.8 \pm 0.1}$ at $53^{\circ} \mathrm{C},[\mathrm{M}]^{1.6 \pm 0.1}$ at $60^{\circ} \mathrm{C},[\mathrm{M}]^{1.7 \pm 0.1}$ at $70^{\circ} \mathrm{C},[\mathrm{M}]^{1.8 \pm 0.1}$ at $80^{\circ} \mathrm{C}$, 
K. ITO

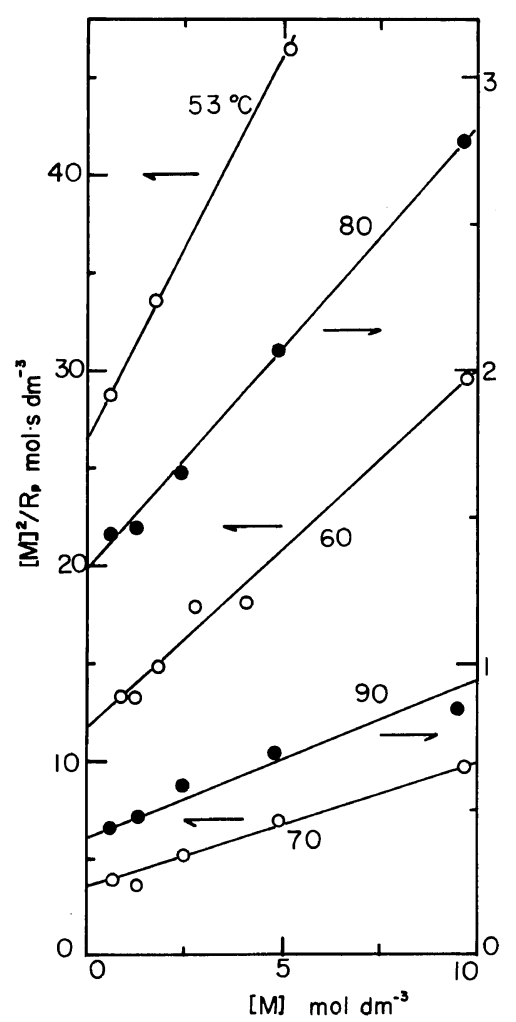

Figure 1. Analysis of polymerization rates by eq 19 .

Table II. Some values calculated for the polymerization of VA initiated by APE

\begin{tabular}{|c|c|c|c|c|}
\hline Temp & $k_{\mathrm{ti}} / 10^{4} k_{\mathrm{i}} k_{\mathrm{p}}$ & $\lambda C_{\mathrm{trC}} / 10^{4} f k_{\mathrm{d}}$ & \multirow{2}{*}{$C_{\mathrm{trC}}$} & \multirow{2}{*}{$f$} \\
\hline${ }^{\circ} \mathrm{C}$ & $\mathrm{dm}^{3} \mathrm{~mol}^{-1} \mathrm{~s}^{-1}$ & $\mathrm{~s}$ & & \\
\hline 53 & 277 & 196 & 0.09 & 0.50 \\
\hline 60 & 120 & 90 & 0.10 & 0.40 \\
\hline 70 & 36 & 30 & 0.12 & 0.37 \\
\hline 80 & 12.7 & 7.90 & 0.13 & 0.37 \\
\hline \multirow[t]{2}{*}{90} & 4.1 & 2.25 & 0.16 & 0.46 \\
\hline & & & \multicolumn{2}{|c|}{$($ mean $=0.42)$} \\
\hline
\end{tabular}

and $[\mathrm{M}]^{1.9 \pm 0.1}$ at $90^{\circ} \mathrm{C}$; it should be independent of [APE] (Table I). Thus, the data should be analyzed by eq 18 . The values of $k_{\mathrm{ti}} / k_{\mathrm{i}} k_{\mathrm{p}}$ and $C_{\mathrm{trC}} / f k_{\mathrm{d}}$ were estimated from the intercept and the slope (Figure 1) and are shown in Table II. The Arrhenius equations are applicable to these values (Figures 2 and $3)$, which are then written as

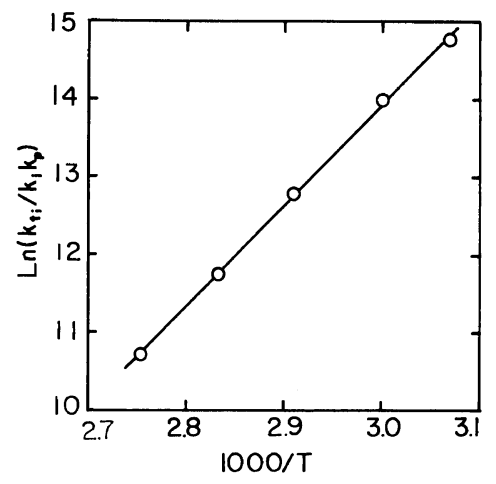

Figure 2. Relationship between $k_{\mathrm{t}} / k_{\mathrm{i}} k_{\mathrm{p}}$ and $T$.

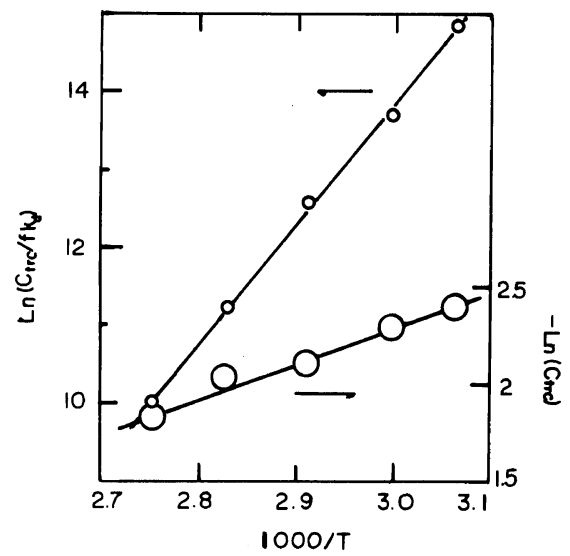

Figure 3. Relationships among $C_{\mathrm{trC}}, f k_{\mathrm{d}}$, and $T$.

$$
\begin{gathered}
\frac{k_{\mathrm{ti}}}{k_{\mathrm{i}} k_{\mathrm{p}}}=6.07 \times 10^{-11} \exp \left(\frac{24800}{R T}\right) \\
\mathrm{dm}^{3} \mathrm{~s} \mathrm{~mol}^{-1} \\
\frac{C_{\mathrm{trC}}}{f k_{\mathrm{d}}}=5.3 \times 10^{-14} \exp \left(\frac{29300}{R T}\right) \mathrm{s}
\end{gathered}
$$

The value of $k_{\mathrm{i}}$ may be estimated by the relation $^{2,5,7}$

$$
k_{\mathrm{i}} \simeq k_{\mathrm{ST}: \mathrm{VAc}}=k_{\mathrm{ST}: \mathrm{ST}} \cdot\left(\frac{k_{\mathrm{ST}: \mathrm{VAc}}}{k_{\mathrm{ST}: \mathrm{ST}}}\right)
$$

At $60^{\circ} \mathrm{C}, k_{\mathrm{i}}$ was found to be $3.0 \mathrm{dm}^{3} \mathrm{~mol}^{-1} \mathrm{~s}^{-1}$ with $k_{\mathrm{ST}: \mathrm{ST}}=164 \mathrm{dm}^{3} \mathrm{~mol}^{-1} \mathrm{~s}^{-1}$ and $k_{\mathrm{ST}: \mathrm{ST}} /$ $k_{\mathrm{ST}: \mathrm{VAc}}=55 .{ }^{9,10}$ The values of $k_{\mathrm{VAc}: \mathrm{VAc}}$ obtained before were. very much scatter. ${ }^{10}$ Because such a scattering was in the range of $k_{\mathrm{p}}=670 \sim 19000 \mathrm{dm}^{3} \mathrm{~mol}^{-1} \mathrm{~s}^{-1},{ }^{10} k_{\mathrm{i}} \ll k_{\mathrm{p}}$ in the 
present polymerization should be completely satisfied.

The above discussion is greatly dependent on the assumption as inequality 15 and thus is examined as follows. Inequality 17 is rewritten as

$$
\frac{k_{\mathrm{p}}^{2}}{\bar{k}_{\mathrm{t}}} \cdot \frac{k_{\mathrm{ti}}}{k_{\mathrm{i}} k_{\mathrm{p}}} \gg \frac{R_{\mathrm{p}}}{2 f k_{\mathrm{d}}[\mathrm{C}]}\left(1+\frac{k_{\mathrm{ti}}}{k_{\mathrm{i}} k_{\mathrm{p}}} \cdot \frac{R_{\mathrm{p}}}{[\mathrm{M}]^{2}}\right)
$$

The left term was calculated to be 100000 at $60^{\circ} \mathrm{C}$, where $k_{\mathrm{p}}{ }^{2} / k_{\mathrm{t}}=0.126 \mathrm{dm}^{3} \mathrm{~mol}^{-1} \mathrm{~s}^{-1}, 9$ $k_{\mathrm{p}}=1980 \quad \mathrm{dm}^{3} \mathrm{~mol}^{-1} \mathrm{~s}^{-1},{ }^{9} \quad k_{\mathrm{i}} \simeq k_{\mathrm{ST}: \mathrm{VAc}}=3.0$ $\mathrm{dm}^{3} \mathrm{~mol}^{-1} \mathrm{~s}^{-1}, \quad$ and $\quad k_{\mathrm{ti}}=4 \times 10^{9}$ $\mathrm{dm}^{3} \mathrm{~mol}^{-1} \mathrm{~s}^{-1}$ as a diffusion-controlled rate constant. ${ }^{11}$ The right term was smaller than 1000 , where $2 f k_{\mathrm{d}}[\mathrm{C}]=4.8 \times 10^{-8}$ was used. $^{2}$ It is apparent that the right term is negligibly smaller than that on the left; thus, inequality 15 is satisfied. In conclusion, under the present conditions, the data cannot be treated by an ordinary equation such as $R_{\mathrm{p}} \propto[\mathrm{C}]^{1 / 2}[\mathrm{M}]$. If $k_{\mathrm{p}}=1980 \mathrm{dm}^{3} \mathrm{~mol}^{-1} \mathrm{~s}^{-1}$ at $60^{\circ} \mathrm{C}$ is used, ${ }^{9}$ the value of $k_{\mathrm{ti}}$ becomes $5.9 \times 10^{9} \mathrm{dm}^{3} \mathrm{~mol}^{-1} \mathrm{~s}^{-1}$. This rate constant is quite reasonable in view of the diffusion-controlled theory. ${ }^{11}$ Here, $k_{\mathrm{p}}=1980$ and was calculated from the most probable Arrhenius equation. This shows that a reasonable value of $k_{\mathrm{ti}}$ can be calculated.

In order to use eq $20, C_{\mathrm{trM}}$ and $C_{\mathrm{trS}}$ must be calculated by ${ }^{12}$

$$
\begin{aligned}
& C_{\mathrm{trM}}=0.0347 \exp (-3450 / R T) \\
& C_{\mathrm{trS}}=0.0351 \exp (-3170 / R T)
\end{aligned}
$$

The ratio $\left(=2 C_{\mathrm{trC}}\right)$ of $\left(1 / \bar{n}-C_{\mathrm{trM}}-C_{\mathrm{trS}}[\mathrm{S}] /[\mathrm{M}]\right)$ to $[\mathrm{C}] /[\mathrm{M}]$ should be constant at a given temperature (Table I). Thus, the first term on the right of eq 20 is not comparable to the second term. Because $1 / \bar{n}$ is considerably larger than $\left(C_{\mathrm{trM}}+C_{\mathrm{trS}}[\mathrm{S}] /[\mathrm{M}]\right)$, the chain length of the polymer produced is controlled by the transfer to APE. The average values of $C_{\mathrm{trC}}$ obtained at given temperatures are shown in Table II. The transfer constant $C_{\text {trC }}$ may also be treated by the following Arrhenius equation (Figure 3) as

$$
C_{\mathrm{trC}}=31 \exp \left(-\frac{3700}{R T}\right)
$$

Equations 24 and 27 give an activation energy of $33.0 \mathrm{kcal} \mathrm{mol}^{-1}$ for $f k_{\mathrm{d}}$. This value is in a very good agreement with the $32.6 \mathrm{kcal} \mathrm{mol}^{-1}$ in an equation such as ${ }^{1}$

$$
k_{\mathrm{d}}=6.43 \times 10^{14} \exp (-32600 / \boldsymbol{R} T)
$$

The value of $f$ can be calculated from those obtained for $C_{\mathrm{trC}} / f k_{\mathrm{d}}$ and $C_{\mathrm{trC}}$, and eq 28 , as shown in Table II and may be independent of temperature $(f \simeq 0.42)$.

The values of $C_{\mathrm{trC}}$ are much larger than those of usual azo initiators. ${ }^{10}$ Perhaps, this is due to the fact that APE has two methenyl hydrogens as $\mathrm{C}_{6} \mathrm{H}_{5} \mathrm{C} \underline{\mathrm{H}}\left(\mathrm{CH}_{3}\right) \mathrm{N}=\mathrm{N}-$ which may be easily abstracted by polyVAc radicals. This is reasonable since the value of $C_{\mathrm{trC}} / 2=$ $0.05\left(C_{\mathrm{trC}}\right.$ is divided by 2 because of two methenyl hydrogens) at $60^{\circ} \mathrm{C}$ is comparable with $C_{\mathrm{trS}}=0.07$ for triphenylmethane ${ }^{13}$ whose methenyl hydrogen can be abstracted to yield triphenylmethyl radicals. Therefore, the transfer reaction may be shown as

$$
\begin{gathered}
\mathrm{N}+\mathrm{HCCH}_{3} \mathrm{C}_{6} \mathrm{H}_{5} \mathrm{~N}=\mathrm{NC}_{6} \mathrm{H}_{5} \mathrm{CH}_{3} \mathrm{CH} \rightarrow \\
\mathrm{HCCH}_{3} \mathrm{C}_{6} \mathrm{H}_{5} \mathrm{~N}=\mathrm{NC}_{6} \mathrm{H}_{5} \mathrm{CH}_{3} \mathrm{C} . \\
+ \text { polymer }
\end{gathered}
$$

The stability of this radical is higher than that of PER and comparable with that of the triphenylmethyl radical, which hardly adds to monomers and inhibits polymerization. ${ }^{14}$ Accordingly, the APE radical does not add to VAc and reacts only with polyVAc radicals. Consequently, the polymerization rate is further decreased by the transfer (29).

\section{NOMENCLATURE}

$$
\begin{array}{ll}
R_{\mathrm{p}} & =\text { polymerization rate } \\
\bar{n} & =\text { chain length (number-average degree of } \\
& \text { polymerization) } \\
{[\mathrm{C}] \quad=} & \text { initiator concentration } \\
{[\mathrm{M}] \quad=} & \text { monomer concentration } \\
{[\mathrm{S}] \quad=} & \text { solvent concentration }
\end{array}
$$


$[\mathrm{R}]=$ primary radical concentration

$[\mathrm{N}]=$ polymer radical concentration

$\left[\mathrm{T}_{\mathrm{A}}\right]=$ small radical produced by transfer to $A(=C$, $M, S)$

$f \quad=$ fraction of primary radical escaping from the solvent cage

$k_{\mathrm{d}} \quad=$ initiator decomposition rate constant

$k_{\mathrm{p}} \quad=$ propagation rate constant

$k_{\mathrm{i}} \quad=$ rate constant for addition of $R$ to $M$

$k_{\mathrm{ti}} \quad=$ rate constant for the primary radical termination between $N$ and $R$

$k_{\mathrm{trt}}=$ rate constant of termination between $T_{\mathrm{C}}$ and $N$

$\bar{k}_{\mathrm{t}}=$ rate constant of termination between $N$ and $N$

$k_{\mathrm{trA}}=$ rate constant of transfer to $A\left(C_{\mathrm{trA}}=k_{\mathrm{trA}} / k_{\mathrm{p}}\right)$

$k_{\mathrm{A}: \mathrm{B}}=$ rate constant of propagation of radical $\mathrm{A}$ to monomer B

$T=$ absolute temperature

$\boldsymbol{R}=$ gas constant

$w_{j} \quad=$ weight fraction of $j$ th species in a polymer

$M_{j} \quad=$ molecular weight of $j$ th species in a polymer

$M_{j s}=$ molecular weight of $j$ th species in polystyrene

$[\eta] \quad=$ intrinsic viscosity

$K, a=$ Mark-Houwink constants for a polymer

$K_{s}, a_{\mathrm{s}}=$ Mark-Houwink constants for a polystyrene standard

$M_{n} \quad=$ number-average molecular weight $\left(=1 / \sum w_{j} / M_{j}\right)$

$M_{w} \quad=$ weight-average molecular weight $\left(=\sum w_{j} M_{j}\right)$

$M_{v}=$ viscosity-average molecular weight $\left[=\left(\sum w_{j} M_{j}^{a}\right)^{1 / a}\right]$

$n \quad \cdot=$ degree of polymerization

\section{REFERENCES}

1. S. G. Cohen, S. G. Groszos, and D. B. Sparrow, $J$. Am. Chem. Soc., 72, 3947 (1950).

2. K. Ito, J. Polym. Sci., Polym. Chem. Ed., 16, 2725 (1978).

3. K. Ito, Polym. J., 11, 795 (1979).

4. K. Ito, Polym. J., 14, 115, No. 7-i (1982).

5. K. Ito, J. Polym. Sci., Polym. Chem. Ed., 15, 2037 (1977).

6. K. Ito, J. Polym. Sci., A-1, 10, 10481 (1972).

7. K. Ito, J. Polym. Sci., Polym. Chem. Ed., 13, 521 (1975).

8. H. K. Mahabadi and K. F. O'Driscoll, J. Appl. Polym. Sci., 21, 1283 (1977).

9. Kh. S. Bagdasa'yan, "Theory of Free-Radical Polymerization," Asakurashoten for Japanese Translation, Tokyo 1964; Israel Scientific Translations, Jerusalem, 1968.

10. J. Brandrup and E. H. Immergut, "Polymer Handbook," John Wiley \& Sons, Inc., New York, N. Y., 1974.

11. G. V. Schulz, Z. Phsik. Chem. Neue Folge, 8, 284 (1957).

12. G. V. Schulz and L. Roberts-Nowakowska, Makromol. Chem., 80, 36 (1964).

13. J. C. Bevington and H. G. Troth, Trans. Faraday Soc., 59, 127 (1963).

14. F. R. Mayo and R. A. Gregg, J. Am. Chem. Soc., 70, 1284 (1948). 